\title{
EFFECTS OF MACROECONOMIC FLUCTUATIONS ON MENTAL HEALTH AND PSYCHOTROPIC MEDICINE CONSUMPTION
}

\author{
Mario Martínez Jiménez \\ Erasmus University Rotterdam, \\ Burgemeester Oudlaan 50, 3062 PA, Rotterdam, Netherlands \\ Judit Vall Castelló*1 \\ Department of Economics and IEB, \\ University of Barcelona, John M.Keynes, 1-11, 08034 Barcelona, Spain \\ CRES-UPF, Ramon Trias Fargas, 25-27, 08005 Barcelona, Spain
}

Manuscript word count: 5,035 words.

Abstract word count: 185 words.

1 *Corresponding author. Judit Vall Castelló. Department of Economics and IEB, University of Barcelona, Spain.E-mail address: judit.vall@ub.edu .Tel.:+34646237956 


\begin{abstract}
:
Our aim in this paper is to understand the impact of macroeconomic fluctuations on mental health and psychotropic medicine consumption. In order to do that we exploit differences in the fluctuations of business cycle conditions across regional units in Catalonia. Our findings suggest that, in general, economic fluctuations at the local level had no significant effect on the consumption of psychotropic medicines. However, we show that a deterioration in local labour market conditions is associated with a reduction in the consumption of anxiolytics medicines. We also report an increase in the consumption of anxiolytics in regions with a softer deterioration in the economic situation. Although we report mild improvements in both mental and physical health for some sub-groups of the population, we also find significant reductions on the probability of sleeping six hours or more. Thus, these elements point towards potential negative effects of local labour market conditions on health in the medium/long term.
\end{abstract}

Keywords: psychotropic consumption, business cycle fluctuations, mental and physical health. 


\section{INTRODUCTION}

Mental health disorders represent an important problem in many developed and developing countries. In a recent review of the literature on global disease, the cost of mental problems was estimated to be between 1 and 2 percent of national health expenditure in the United States, Europe and the United Kingdom. In 2001, the World Health Organization (WHO) highlighted the urgency of finding effective treatments and preventive strategies for mental health diseases and encouraged investment in research to shed some light on the causes and consequences of mental disorders (World Health Organization, 2001).

One of the potential factors affecting the incidence of mental disorders is macroeconomic fluctuations. There is extensive literature analyzing the impacts of business cycle conditions on physical health of the population. A relatively small subset of this literature has focused on the impacts of becoming unemployed on mental health. Evidence from individual-level data indicates that losing a job -for reasons unrelated to health-increases the individual risk of suffering depression (Burgard et al., 2007; 2009). However, the evidence is inconsistent when it examines the effect of aggregate economic fluctuations on mental health status of the population. Therefore, the net population impact of business cycles on depression symptoms remains speculative and the lack of empirical data calls out for further research. (GoldmanMellor et al., 2010).

Thus, in this paper we contribute to this literature by exploring the effect of very strong economic fluctuations at the local level on the mental and physical health status of the population, as well as on their consumption of psychotropic medicines -antidepressants and anxiolytics-. In order to identify the effects, we focus on a region, Catalonia, of a country, Spain, that experienced a deep economic downturn in the late 2000's, with unemployment 
rates increasing from $8.2 \%$ in 2007 to $24 \%$ in 2013 . During this period the youth unemployment rate reached levels of more than $50 \%$ in 2014 , which represents one of the highest rates in Europe. The severity of the economic fluctuations in Spain will allow us to better identify the existence of mental health effects as a result of business cycle conditions. We use data from the Catalan Health Survey from 2010 to 2015 -2 surveys per year- and exploit differences in the regional incidence of the economic fluctuations across local units in Catalonia (31 regional units) to identify the effects of local changes in the economic situation on mental health and psychotropic medicine consumption. Our findings suggest that, in general, the severity of the economic crisis at the local level had no significant effect on the consumption of psychotropic medicines (antidepressants and anxiolytics) or on mental health symptoms. However, we do report that a deterioration in local labour market conditions is associated with a reduction in the consumption of anxiolytic medicines for individuals aged between 20 and 35 years old, which also report increases in good selfassessed health. On the other hand, we also report that the consumption of anxiolytics significantly increases in those regions in which the deterioration of the economic situation is softer.

Although we report mild improvements in both mental and physical health for some subgroups of the population, we also find significant reductions on the probability of sleeping six hours or more, on the probability of having private insurance as well as on the probability of being married. Thus, these elements point towards potential negative effects of local labour market conditions on health in the medium/long term.

In theory, during an economic downturn disposable income drops and living conditions may deteriorate leading to the enlargement of mental health problems. Similarly, even those individuals that manage to keep their jobs may suffer from increased levels of stress and 
anxiety due to the prospects of losing their jobs in the near future. On the other hand, however, when the economy slows down individuals that become unemployed may use their free time to practice more exercise or to do some other health enhancing activity - such as cooking more home meals- which may, in turn, improve mental health outcomes.

Focusing on Spain, the article by Rivera et al. (2017) explores the link between the economic crisis and suicide rates. Using mortality data due to suicides from the Spanish National Institute of Statistics for the years 2002-2013, the authors find that the recent economic recession lead to an increase in the suicide rate in Spain by 9\% in 2013. Also for Spain, Bartoll et al. (2014) compare two waves of the Spanish National Health Survey to estimate the impact of the economic crisis on mental health using the GHQ-12 index. The authors use one pre-crisis wave, collected in 2006-2007 and compare the mental health status with a postcrisis wave, collected in 2011-2012. They report an increase in the prevalence of poor mental health among Spanish men. The paper by Urbanos-Garrido and Lopez-Valcarcel (2015) compare the same two waves of the Spanish National Health Survey (2006-2007 versus 2011-2012) and uses a matching technique to identify the impact of the economic crisis on mental health with a special focus on long-term unemployment. The authors find that longterm unemployment has a large and significant negative effect on both self-assessed and mental health and, these negative effects are significantly worse during the economic crisis. In Gili et al. (2012) the authors randomly select a sample of 7,940 patients attending primary care centers in Spain in 2006-2007 and compare the answers to the Primary Care Evaluation of Mental Disorders instrument with a sample of 5,879 patients in 2010-2011. The authors find an increase by $19.4 \%$ in the number of patients with depression, an increase by $8.4 \%$ in the number of patients with anxiety disorders, an increase by $7.3 \%$ in somatic symptoms and an increase by $4.6 \%$ in disorders related to alcohol consumption. 
Looking at the evidence for other settings, Wang et al. (2018) use the PSID to study the impact of the Great Recession on health outcomes in the United States. The authors conclude that the economic crisis increased reports of poor health and had an adverse impact on mental health. Also for the USA, Mckenzie et al. (2014) use panel data and compare the mental health status of the population before and during the economic crisis (2004-2009). The authors show that the financial crisis, which decreased household incomes and increased unemployment, lead to a deterioration of self-perceived mental health in the short term.

In contrast, there is a second strand of the literature that reports that economic downturns are not translated into worse mental health conditions. The idea is that being unemployed provides individuals with an opportunity to invest time in looking for better work opportunities or having a healthier life leading to a reduction of mental health problems caused by stressful job conditions. Ruhm $(2000,2005,2016)$ has documented this relation with respect to mortality and several health outcomes. This health enhancing effect of economic recessions has also been documented at European level. For example, Astell-Burt and Freg (2013) using data from a sample of the United Kingdom population for the period 2006-2010 determine that recessions have a negligible effect on mental health and Ásgeirsdóttir et al. (2016) find that, in Iceland, most health behaviours improved during the economic crisis of 2008 but all of them, except binge drinking, reverted back to their precrisis level by the time of the economic recovery in 2012. Finally, Goldman-Mellor et al. (2010) review the accumulated evidence concerning the relation between economic fluctuations and mental health for a large group of countries. The authors report that the impact of economic contractions -measured by the unemployment rate- on depression symptoms remains inconclusive. 
If mental health is indeed affected by changes in business cycle conditions, then psychotropic medicines (antidepressant and anxiolytics) that are used to mitigate the effects of these mental health disorders can also experience changes during economic fluctuations. For instance, the "Nuffield Trust and Health Foundation's QualityWatch" in the UK find a substantial increase (by $8.5 \%$ ) in the number of antidepressant prescriptions during the economic crisis. In Spain, according to the Spanish ${ }^{2}$ Medicines and Health Agency (AEMPS), the use of antidepressant medicines has tripled in the past 10 years; going from 26.5 number of pills per 1,000 inhabitants per day (DHD) in 2000 to 79.5 pills consumed in 2013. Similarly, Gili et al. (2014) highlight that antidepressant sales in Spain increased by 10\% between 2009 and 2012 and the sales of hypnotic and anxiety medicines increased by $3.6 \%$ in 2009 and by $4.5 \%$ in 2010 (although this growth has declined in 2011 and 2012). According to the Catalan Health System observatory, the consumption of antidepressants in Catalonia increased in all age groups (except over 75 years old) from 2006 to 2011 and decreased between 2011 and 2013. Of course, the global trends in the consumption of these medicines may be partly related to business cycle fluctuations but many other factors may be having an effect of the evolution of its consumption.

Although the literature on the impacts of business cycle fluctuations on psychotropic medicines consumption is scarcer, the results are also uncertain and mixed. For example, focusing on a sub-region in Catalonia and using a population cohort dataset from a consortium of primary health care centers, Barceló et al. (2016) compare psychotropic medicine consumption in 2005-2008 and 2009-2012. The authors report an increase in the

\footnotetext{
${ }^{2}$ It should be noticed that, in Spain, mental healthcare is an integral part of the general healthcare with universal coverage funded by taxation (Salvador-Carulla et al., 2006). Moreover, general practitioner doctor can offer psychotropic treatments as part of their service, especially in patients who suffer anxiety or depression.

${ }^{3}$ See further information in: https://www.aemps.gob.es/.
} 
consumption of psychotropic medicines in the period following the economic crisis -post 2009- which is especially high for those who were already consuming these medicines before 2009. Martin-Bassols et al. (2016) use very rich survey data on recreational medicine consumption in Spain and explore the impact of the economic crisis at the local level on that consumption. The authors find a significant relation between poor local economic conditions and strong increases in the consumption of marijuana and cocaine in the 2008 economic downturn. In the same way, Colell et al., (2015) report a huge increase in the use of hypnotics/sedatives among employed men and older women during a period of economic recession in Spain. This relationship is also found for the case of the USA; Carpenter et al. (2017) show how the economic crisis lead to increases in substance use disorders related to hallucinogens and prescription pain relievers, as well as, opioid deaths (Simon, 2017).

However, the paper by Arroyo (2016) uses a sample of the Spanish National Health Survey and concludes that the financial crisis does not have a significant effect on the consumption of psychotropic medicines. Therefore, the literature on the impact of the economic crisis on psychotropic medicine consumption is also mixed.

We believe our paper provides new evidence on the relationship between economic conditions and mental health and psychotropic medicine consumption. As reviewed above, most of the literature focuses on the impact of the overall economic crisis and exploits only the temporal evolution of the crisis at the national level. Thus, we go one step further than the literature by exploiting both the temporal as well as the regional evolution of the economic cycle. In order to do that, we focus on local changes in business cycle conditions, which allow us to better isolate the effect of changes in economic conditions on mental health and the consumption of antidepressants and anxiolytics. Furthermore, the papers for Spain reviewed above use two cross-sectional data points to estimate the effects of national business 
cycle fluctuations while we are able to include information on two waves for each year from 2010 to 2015 . Thus, thanks to the richness of our database, we are able to capture in a very detailed manner the evolution of the economic cycle at the local level as well as any contemporaneous changes in mental health and medicines consumption.

Finally, while our results are in line with several papers in the literature pointing towards mild improvements in current health as a result of deteriorations in the local labour market conditions, we also present novel evidence on the potential negative effects on health in the medium/long term as a result of a reduction in the probability of sleeping six hours or more, a drop in the probability of having private health insurance and a reduction in the probability of being married. Thus, this paper helps us advance our understanding of the impact of local business cycle conditions in the near future.

\section{DATA AND ECONOMETRIC STRATEGY}

\subsection{Database.}

We use data from the Catalan Health Survey (ESCA) which is a cross-sectional populationbased face to face survey to adults ( $\geq 15$ years old) from Catalonia, Spain. The data is collected twice per year from 2010 to $2015^{4}$. The Catalan Health Survey includes a wide range of information related to personal characteristics as well as health behaviors and health status. In particular, there are questions on health status, health behaviors and the use of healthcare services. With respect to personal characteristics there is information on family status, age, gender, employment status, region of residence as well as some additional personal characteristics. The information is collected through personal interviews in the

\footnotetext{
${ }^{4}$ Individuals cannot be followed over time.
} 
interviewees' homes. Since July 2010, each year includes about 5,000 interviews (two waves per year ${ }^{5}$ ). The ESCA is conducted by the Catalan Health Department and in collaboration with the Spanish National Institute of Statistics (INE). This survey is particularly useful to answer our question because it includes several depression and anxiety variables which allow us to approximate the mental health status of the population as well as information on psychotropic medicine consumption, which is missing in many health surveys. From Table 1 it can be seen that the sample has 2,426 individuals for the second wave of $2010,4,701$ individuals in the two waves of $2011,4,746$ individuals in the two waves of $2012,4,750$ individuals for the waves in 2013, 4,722 for 2014 and 5,504 for 2015.

To capture the effect of the economic conditions on mental health status as well as psychotropic medicine consumption of the population, we use three different groups of dependent variables. The first group represents the variables that capture consumption of psychotropic medicines; consumption of anxiolytics and consumption of antidepressants. Anxiolytics medicines are defined as substances aimed at calming anxiety and agitation without demising the level of conscious. We excluded the consumption of tranquillizers because its incidence is close to zero in our sample. Antidepressants are defined as all medicines that are used to treat depression. Those variables are equal to one if the individual has consumed or has been prescribed with the relevant medicine in the last two days (see Table $1 \mathrm{~A}$ in the appendix for a detailed description of the definitions and categorizations of all the variables included in the analysis).

The second group of dependent variables aims at capturing both the mental and physical health status of the population interviewed. This group includes two main variables: the risk

\footnotetext{
${ }^{5}$ Except for 2010 in which the survey is collected only once.
} 
of having poor mental health using a Mental Health Index (GHQ-12) which is derived from the "Golberg General Health Questionnaire". This 12-item index is the most extensively used instrument for common mental disorders. The GHQ-12 questionnaire includes 12 questions aimed at detecting symptoms of anxiety, depression or insomnia and it moves on a 12 point scale from 0 to 12 . A score of more or equal than 6-points is associated with worse mental health. The survey includes a binary version of the GHQ-12 index which is 0 for individuals with a normal mental health evaluation and 1 for individuals that score high in the GHQ-12 scale and are defined to be at risk of poor mental health. In the analysis we use this second version of the GHQ-12 (the binary one). The second variable that is included is self-reported and captures the individual impression about their mental health status. The individual is asked about whether he/she thinks that he/she suffers from depression or anxiety, even if those diseases are undiagnosed. Thus, if the individual responds in an affirmative way to either one of the self-reported mental diseases (depression and anxiety) or to both of them, the depression variable is equal to one. Finally, we also include two additional variables that aim at capturing the general and physical health status of the individual. The first one is self-assessed health status while the second one identifies whether the individual suffers from a chronic illness.

The third group of dependent variables is related to individual health behaviors. This group is composed by a variable that evaluates whether the individual gets enough sleep (a dummy variable for whether the individual sleeps more than 6 hours per day ${ }^{6}$ ); a dummy variable to capture whether the individual currently smokes; and a dummy variable to assess whether

\footnotetext{
${ }^{6}$ We use 6 hours per day as a measured of enough sleep because of, according to Möller-Levet et al. (2013), sleeping less than six hours can have a broad negative impact on long-term well-being.
} 
the individual practices any physical activity. Table $1 \mathrm{~A}$ in the appendix section includes a detailed description and categorization of all the variables included in the analysis.

Our variable of interest is the unemployment rate at the local level, which has been collected from the Catalan Institute of Statistics for each of the trimesters, years and regional units (31) included in the survey. We then link it with each individual in the survey according to the regional unit where he/she lives and the trimester-year in which he/she answers the questionnaire. Apart from that, we also include fixed effects for each trimester-year and for each of the regional units in order to capture any fixed differences in health status or medicine consumption behavior across regional units in Catalonia as well as for any trends in these outcome variables that affects the entire territory during the period analyzed. As independent variables we include age group dummies and gender dummies (these variables are also described in more detail in the annex section).

Thus, the local unemployment rate will capture the impact of changes in business cycle conditions at the local level on psychotropic medicine consumption and mental health of individuals living in that regional unit. With this fixed-effect model we will be able to answer our research question of the effect of the economic crisis at the local level on psychotropic medicine consumption, health status and individual health behaviors. Finally, we include four variables to explore potential mechanisms for the results that we find: net monthly household income (a categorical variable which includes 10 income brackets; see Table 1A for details), employment status (1 if employed and zero otherwise), private health insurance (a dummy variable equal to one if the individual has any type of private health insurance on top of the publicly available health system) and married (which is one if the individual is married).

Table 3 shows the descriptive characteristics of our sample. The dataset includes 27,359 observations. We can see in the table that $50.2 \%$ of the sample are men and mean age is 40 
years old. The percentage of people consuming psychotropic medicines is non-negligible as the mean consumption of antidepressants in our sample is $6.4 \%$ and $7.8 \%$ for anxiolytics medicines. The incidence of self-reported depression is also relatively high at $14.2 \%$ of the sample while the GHQ situates the incidence of risk of having poor mental health at $7.6 \%$ of the sample. $81.5 \%$ of individuals in the sample report to be in good self-assessed health and $62.3 \%$ claim to have a chronic disease. With respect to the health behaviour variables, we can see that $18.1 \%$ of the sample reports practicing psychical activity, $20.8 \%$ are current smokers and $93.5 \%$ regularly sleep more than 6 hours per day.

Our variable of interest, the unemployment rate at the regional level has a mean of $14.28 \%$ during our sample period but the broad time horizon of the data ensures an unequal variation in business cycle conditions across regions ${ }^{7}$. This can be seen in Figure 1 that plots the percentage point change in the unemployment rate for each regional unit analysed during our sample period -calculated as the difference between the maximum and the minimum unemployment rate for each region in our sample period. ${ }^{8}$

From Table 3 we can also see that the prevalence of consumption of each psychotropic medicine varies by gender and by the type of substance considered. In particular, consumption of anxiolytics medicines is higher than antidepressants medicines for both genders. The prevalence of women taking antidepressants is roughly $9 \%$ while male prevalence is only $3.75 \%$. This trend is consistent for the mental and physical health

\footnotetext{
${ }^{7}$ It should be noted that the most disaggregated regional variable provided by ESCA is the Territorial Health Government (GTS), which its main aim is to promote the interaction between Government, Administration and citizens, and is composed by 37 health regions. However, we used 31 regions as some of them are merger in order to match with their specifically unemployment rate. For instance, there are 4 GTS for the area of Barcelona.

${ }^{8}$ Figure 2 plots the evolution of the unemployment rate in Catalonia and in Spain and we can see that the evolution is very similar. Furthermore, figure 3 plots the evolution of the unemployment rate in the four provinces in Catalonia. As it can be seen, there are regional differences in business cycle conditions within Catalonia.
} 
dependent variables under consideration, while males show higher levels of smoking and physical activities compared to females.

\subsection{Econometric strategy.}

The statistical method used to capture the effect of psychotropic medicines consumption is specified as a fixed effect model. As all our dependent variables are binary (except for household income), we estimate a fixed effects logistic regression model and report marginal effects in all tables of results. As mentioned above, we use three groups of dependent variables: consumption of psychotropic medicines, mental/physical health status and health behaviors and we also estimate the model on four additional dependent variables to explore the mechanisms at play. Standard errors are clustered at the regional unit level. Thus, we estimate the following regressions:

$$
Y_{i t m}=\alpha+\beta U R_{t m}+\delta X_{i t m}+\gamma M_{m}+\theta T_{t}+\varepsilon_{i t m}
$$

Where $\mathrm{Y}$ is one of the dependent variables for each individual " $i$ " in each period " $t$ " living in region " $m$ ". In all our regressions we include fixed effects for the regional unit (M) and year (T) as well as some individual controls, (X's): age group dummies and gender. Our variable of interest is the unemployment rate of region " $\mathrm{m}$ " at time " $\mathrm{t}$ ". We use the regional unemployment rate to minimize the endogeneity problems of using the individuals own employment/unemployment situation. The idea behind this choice is that if your region is affected by a negative economic situation in a stronger manner, then you are more likely to become unemployed even if you are a very efficient and disciplined employee (so independently of your personal skills or motivation).

In order to identify some potential additional heterogeneous effects across several population groups, we also estimate the same models for different subsamples of the population: for 
different age groups, for men and women and for regions with a stronger/softer increase in the unemployment rate.

\section{RESULTS}

\subsection{Psychotropic consumption and mental health.}

Table 4 shows the results of the impact of local business cycle conditions on the consumption of antidepressants as well as anxiolytic medicines (column 1 and 2). We can see that, although the two coefficients are negative, they are not significant. This suggests that local business cycle conditions do not have a significant effect on the consumption of antidepressants or anxiolytic medicines.

Table 4 also displays the results of the estimations when the dependent variables are those related to the mental health outcomes of the individual. Colum 3 and 4 focus on mental health problems with the variable that captures self-declared incidence of depression (column 3) and the risk of poor mental health problems using GQH-12 index (column 4). While, column 5 shows the probability of sleeping more than six hours per day. As before, none of the coefficients is significant, pointing towards no relation between business cycle conditions at the local level and self-reported depression or the risk of poor mental health.

\subsection{Physical health, SAH and health behaviors.}

Columns 1 and 2 of Table 5 report the results of the physical health variables; the existence of chronic illness (column 1) and positive self-assessed health (column 2). Again, our results show no statistically significant relationship between physical health and the unemployment rate. Finally, columns 3 and 4 report results for the dependent variables that capture individual health behaviors. In particular, we analyze the impact of business cycle 
fluctuations at the local level on the probability of exercising physical activities and the probability of being a smoker. We can see that none of the health behaviors show a significant association with business cycle conditions.

\section{HETEROGENEOUS RESULTS AND MECHANISMS}

In Tables 6 and 7 we present the same baseline results but for sub-groups of the population. In particular we estimate the model separately for men and women, for age groups 20 to 35 , 35 to 50,50 to 65,65 to 80 and 80 and above, for regions with a strong increase in UR and for those with a softer increase in UR. ${ }^{9}$ Our aim in this section is to explore the existence of different responses to local economic shocks by different subsamples.

Table 6 reports the heterogeneous results for the dependent variables of the consumption of antidepressant and anxiolytic medicines. From the two dependent variables analyzed, we find that individuals aged 20-35 are significantly less likely to consume anxiolytic medicines when local economic conditions deteriorate. This is consistent with the findings in Table 7 which report increases in the likelihood of reporting being in good health for this same age group of individuals. However, we also report that the consumption of anxiolytics significantly increases - by 0.9 percentage points- in those regions in which the deterioration of the economic situation is softer.

With respect to the gender dimension, we can see that the incidence of suffering depression or anxiety symptoms is lower for men during recessions (Table 7). Similarly, for the age group 80 and above, we observe a reduction in the probability of suffering from a chronic

\footnotetext{
${ }^{9}$ We define this variable as a dummy variable that takes value 1 if the region experiences an increase in the unemployment rate above the mean during our sample period and zero otherwise.
} 
illness. These results go in line with the literature reporting improvements in physical health when the economic situation gets worse.

For men as well as for age groups 20-35 and 35-50, we document decreases in the probability of sleeping more than 6 hours when the local economy deteriorates, as well as increases in the probability of smoking for the age range 65 to 80 (see Table 7). These results point towards potential negative effects on health in the medium/long term.

When we study the potential mechanisms behind the results on mental and physical health, we can see in Table 8 that there is a clear reduction in monthly household income as well as in the probability of being employed for almost all groups. Even if this impact is not significant, we believe that the results should be interpreted with care as the data only includes self-reported information on both income and employment status.

On the other hand, there is a clear reduction in the probability of having private health insurance (on top of the publicly available health system) which is highly significant for males, individuals in the age group 35-50 and in regions with a stronger incidence of the negative economic conditions. There is also a reduction in the probability of being married for the age group 35-50 as a result of the increase in the local unemployment rate. Given the protective effect of marriage (or partnership more generally) on health as well as the observed lost of private health insurance, the negative effects of business cycle fluctuations at the local level may only fully materialize in the medium/long term.

\section{CONCLUSIONS}

In conclusion, in our paper we document that local changes in the economic situation during the period 2010-2015 are not significantly associated with changes in the risk of using 
psychotropic medicines -antidepressant and anxiolytic medicines- for the general population. When we look at the effects for particular sub-groups of the population, we do find that deteriorations in local labour market conditions are associated with a lower likelihood of consuming anxiolytic medicines for individuals aged 20 to 35 years old. For this group of individuals, we also show increases in the probability of reporting good selfassessed health. However, we also report that the consumption of anxiolytics significantly increases -by 0.9 percentage points- in those regions in which the deterioration of the economic situation is softer.

Although we report mild improvements in both mental and physical health for some subgroups of the population, we also find some elements that point towards potential negative effects of local labour market conditions on health in the medium/long term; for instance, we find significant reductions in the probability of sleeping at least six hours as well as strong reductions in the probability of having private health insurance and the probability of being married. Although migration out of the area of study (Catalonia) might pose a threat to our identification, Figure 4 shows evidence of a very stable population pattern during our sample period.

We believe that our results are in line with several papers in the literature pointing towards mild improvements in current health as a result of deteriorations in the local labour market conditions although we also present novel evidence on the potential negative effects on health in the medium/long term. Thus, this paper helps us advance our understanding of the impact of business cycle conditions in the near future, which represents an important piece of information for governments when considering the best policies to apply to protect the mental health of their citizens when faced with the next economic recession. However, a note of caution should be made with respect to the external validity of our estimates as our results 
are obtained with data of only one country, Spain, affected by a particularly strong economic recession. 


\section{References}

- Arroyo Borrell, E. (2016). Health and economic conditions: evidence from individual-level data.

- Ásgeirsdóttir, T. L., Corman, H., Noonan, K., \& Reichman, N. E. (2016). Lifecycle effects of a recession on health behaviors: Boom, bust, and recovery in Iceland. Economics \& Human Biology, 20, 90-107.

- Astell-Burt, T., \& Feng, X. (2013). Health and the 2008 economic recession: evidence from the United Kingdom. PLoS One, 8(2), e56674.

- Barcelo, M. A., Coll-Negre, M., Coll-de-Tuero, G., \& Saez, M. (2016). Effects of the financial crisis on psychotropic drug consumption in a cohort from a semi-urban region in Catalonia, Spain. PloS one, 11(2), e0148594.

- Bartoll, X., Palencia, L., Malmusi, D., Suhrcke, M., \& Borrell, C. (2013). The evolution of mental health in Spain during the economic crisis. The European Journal of Public Health, 24(3), 415418.

- Burgard, S. A., Brand, J. E., \& House, J. S. (2007). Toward a better estimation of the effect of job loss on health. Journal of health and social behavior, 48(4), 369-384.

- Burgard, S. A., Brand, J. E., \& House, J. S. (2009). Perceived job insecurity and worker health in the United States. Social science \& medicine, 69(5), 777-785.

- Goldman-Mellor, S. J., Saxton, K. B., \& Catalano, R. C. (2010). Economic contraction and mental health: A review of the evidence, 1990-2009. International Journal of Mental Health, 39(2), 6-31.

- Carpenter, C. S., McClellan, C. B., \& Rees, D. I. (2017). Economic conditions, illicit drug use, and substance use disorders in the United States. Journal of Health Economics, 52, 63-73.

- Colell, E., Sánchez-Niubò, A., Delclos, G. L., Benavides, F. G., \& Domingo-Salvany, A. (2015). Economic crisis and changes in drug use in the Spanish economically active population. Addiction, 110(7), 1129-1137.

- Gili, M., García, J. C., \& Roca, M. (2014). Economic crisis and mental health. SESPAS report 2014. Gaceta sanitaria, 28, 104-108.

- Gili, M., Roca, M., Basu, S., McKee, M., \& Stuckler, D. (2012). The mental health risks of economic crisis in Spain: evidence from primary care centres, 2006 and 2010. The European Journal of Public Health, 23(1), 103-108. 
- Simon, K. (2017). MACROECONOMIC CONDITIONS AND OPIOID ABUSE Alex Hollingsworth Christopher J. Ruhm.

- Bassols, N. M., \& Castelló, J. V. (2016). Effects of the great recession on drugs consumption in Spain. Economics \& Human Biology, 22, 103-116.

- McInerney, M., Mellor, J. M., \& Nicholas, L. H. (2013). Recession depression: mental health effects of the 2008 stock market crash. Journal of health economics, 32(6), 1090-1104.

- Mckenzie, S. K., Gunasekara, F. I., Richardson, K., \& Carter, K. (2014). Do changes in socioeconomic factors lead to changes in mental health? Findings from three waves of a population based panel study. J Epidemiol Community Health, 68(3), 253-260.

- Möller-Levet, C. S., Archer, S. N., Bucca, G., Laing, E. E., Slak, A., Kabiljo, R., ... \& Dijk, D. J. (2013). Effects of insufficient sleep on circadian rhythmicity and expression amplitude of the human blood transcriptome. Proceedings of the National Academy of Sciences, 110(12), E1132E1141.

- Salvador-Carulla, L., Garrido, M., McDaid, D., \& Haro, J. M. (2006). Financing mental health care in Spain: context and critical issues. The European journal of psychiatry, 20(1), 29-44.

- Rivera, B., Casal, B., \& Currais, L. (2017). Crisis, suicide and labour productivity losses in Spain. The European Journal of Health Economics, 18(1), 83-96.

- Ruhm, C.,2000. Are recessions good for your health?. The Quarterly journal of economics; vol. 115 (2), pp. 617-650.

- Ruhm, C., 2005. Healthy living in hard times. Journal of Health Economics; vol. 24 (2), pp. 341363.

- Ruhm, C., 2015. Recessions, healthy no more? Journal of Health Economics; vol. 42, pp. 17-28.

- Urbanos-Garrido, R. M., \& Lopez-Valcarcel, B. G. (2015). The influence of the economic crisis on the association between unemployment and health: an empirical analysis for Spain. The European Journal of Health Economics, 16(2), 175-184.

- Wang, H., Wang, C., \& Halliday, T. J. (2018). Health and health inequality during the Great Recession: Evidence from the PSID. Economics \& Human Biology, 29, 17-30.

- World Health Organization. (2001). The World Health Report 2001: Mental health: new understanding, new hope. World Health Organization.

- [dataset] Garcia, O., Masachs, E., Medina, A., Mompart, A., Saltó, E., Schiaffino, A., Tresserras, R., 2011-2016. Catalan Health Survey, 2010-2015. Catalan Health Department. 


\section{Tables and Figures}

Figure 1. Percentage point increase in unemployment rates during the period of study. Calculated as the difference between the maximum and the minimum value of the unemployment in our sample for each regional unit.

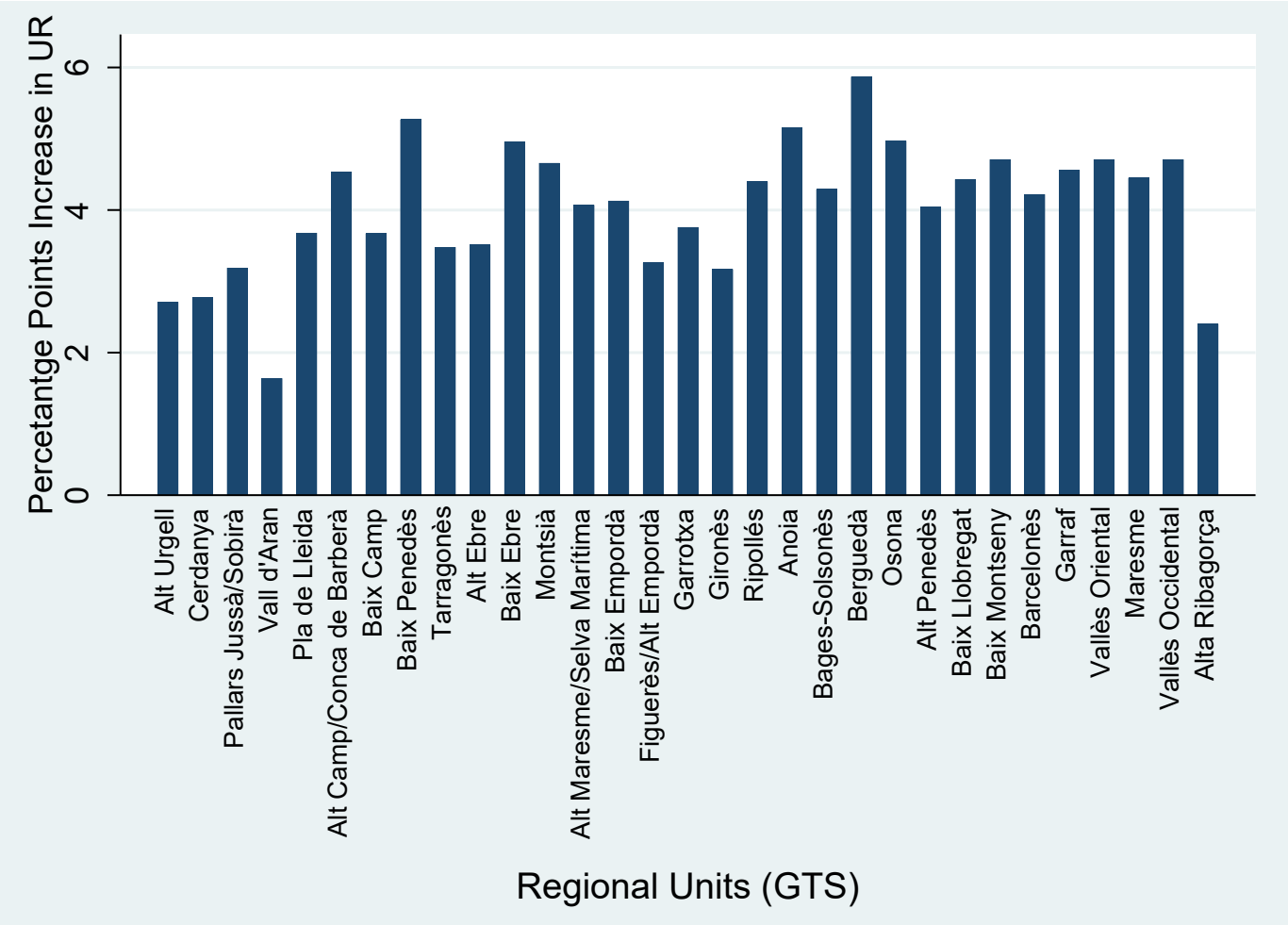

Source: Catalan Institute of Statistics (IDESCAT). 
Figure 2. Evolution of the unemployment rate in Catalonia and Spain by trimester during our sample period.

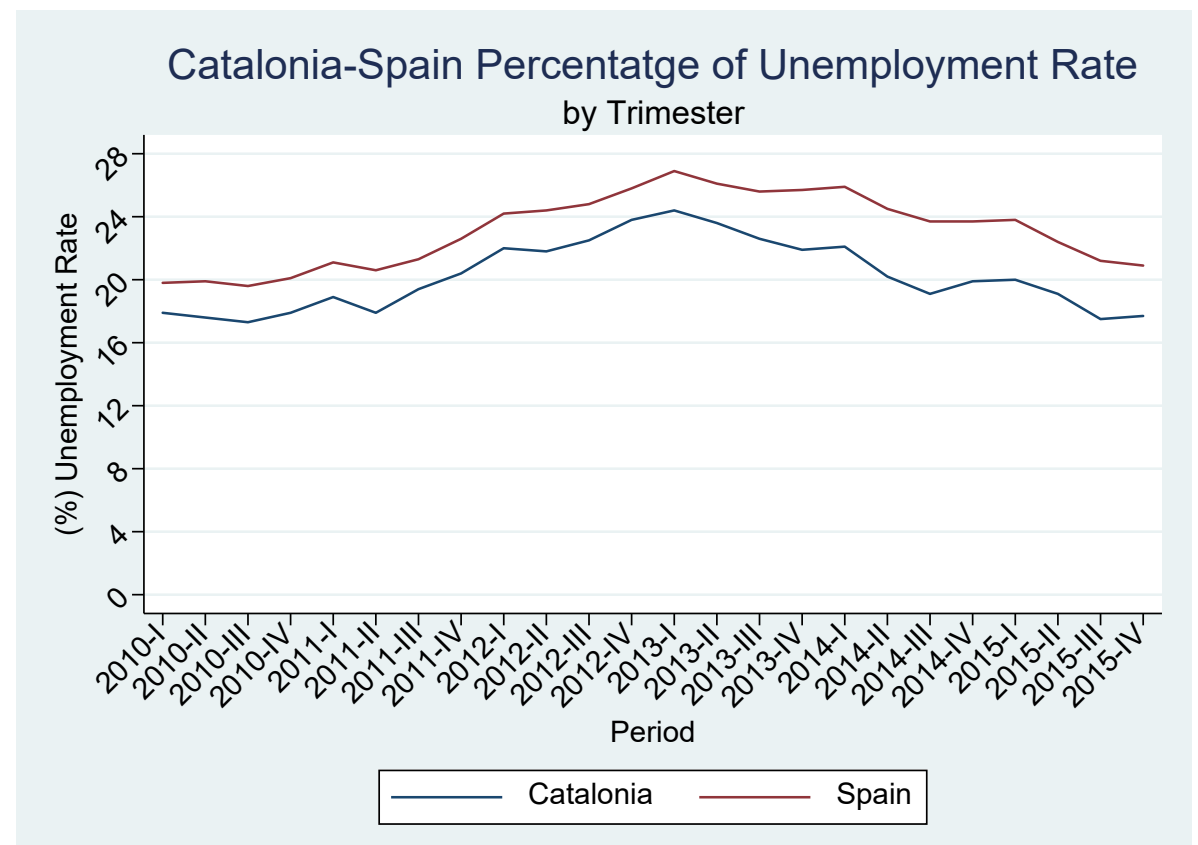

Source: National Institute of Statistics.

Figure 3. Evolution of the employment rate in Catalonia by provinces during our sample period.

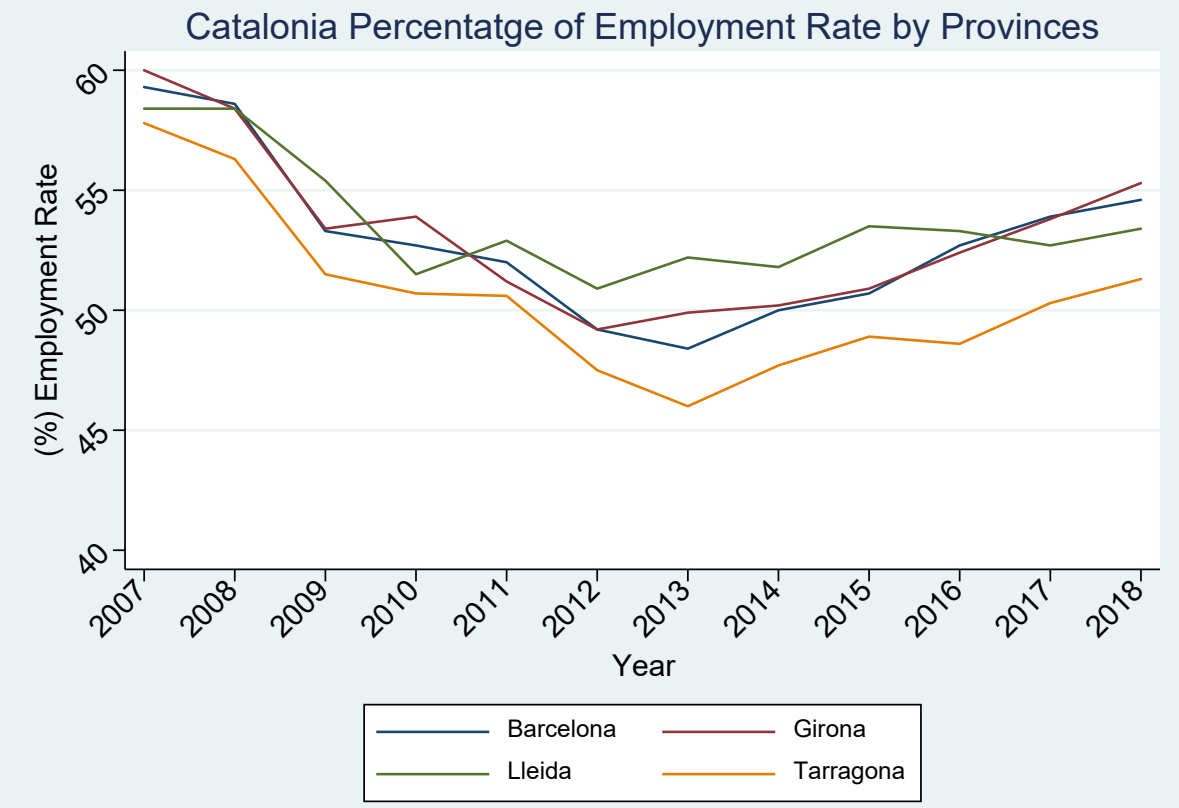

Source: Catalan Institute of Statistics (IDESCAT). 
Figure 4. Evolution of the number of inhabitants in Catalonia during our sample period.

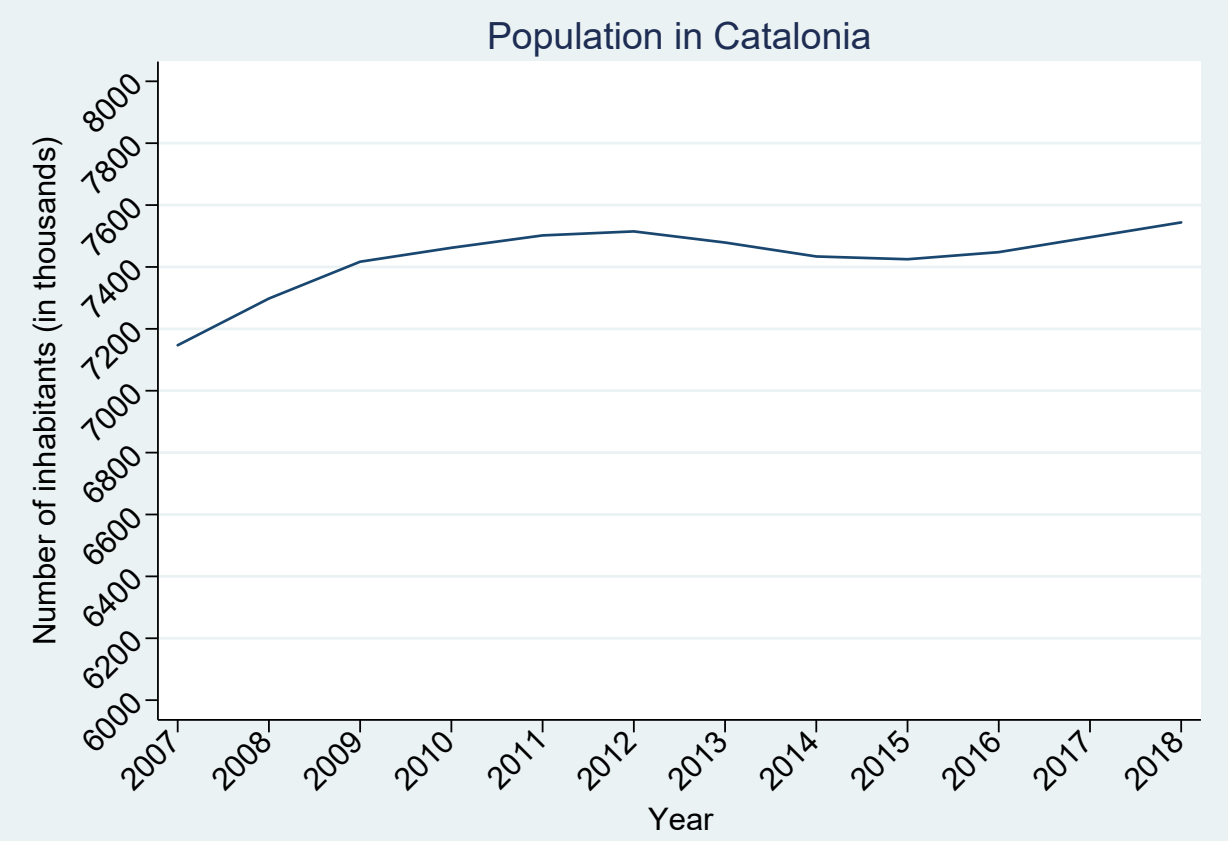

Source: Catalan Institute of Statistics (IDESCAT). 
Table 1. Description of the survey years included and the observations for each wave.

\begin{tabular}{|c|c|c|c|c|c|c|c|c|c|c|c|c|}
\hline \multirow{2}{*}{$\begin{array}{c}\text { Year } \\
\text { Number of } \\
\text { surveys }\end{array}$} & \multicolumn{2}{|c|}{2010} & \multicolumn{2}{|c|}{2011} & \multicolumn{2}{|c|}{2012} & \multicolumn{2}{|c|}{2013} & \multicolumn{2}{|c|}{2014} & \multicolumn{2}{|c|}{2015} \\
\hline & $I$ & II & $I$ & II & $I$ & II & $I$ & II & $I$ & II & $I$ & II \\
\hline Observations & - & 2,426 & 2,302 & 2,399 & 2,465 & 2,281 & 2,354 & 2,396 & 2,308 & 2,414 & 2,387 & 3,117 \\
\hline
\end{tabular}

Source: ESCA survey waves 2010-2015.

Table 2. Representativeness of Survey. Some population and sample characteristics.

\begin{tabular}{|c|c|c|c|c|c|c|}
\hline \multirow[b]{2}{*}{$\begin{array}{l}\text { Age } \\
\text { group }\end{array}$} & \multicolumn{3}{|c|}{ Population ( $1^{\text {st }}$ January 2016) } & \multicolumn{3}{|c|}{ Surveys 2010-2015 } \\
\hline & Male & Female & Total $(\%)$ & Male & Female & Total \\
\hline $15-44$ & $1,524,347$ & $1,464,327$ & $\begin{array}{c}2,988,674 \\
(47.25)\end{array}$ & 5,287 & 4,989 & $\begin{array}{c}10,276 \\
(46.37 \%)\end{array}$ \\
\hline $45-64$ & 978,306 & 996,793 & $\begin{array}{l}1,975,099 \\
(31.22 \%)\end{array}$ & 3,397 & 3,352 & $\begin{array}{c}6,749 \\
(30.46 \%)\end{array}$ \\
\hline $\begin{array}{l}64 \text { and } \\
\text { more }\end{array}$ & 580,371 & 781,246 & $\begin{array}{l}1361617 \\
(21.53 \%)\end{array}$ & 2,412 & 2,722 & $\begin{array}{c}5,134 \\
(23.17 \%)\end{array}$ \\
\hline Total (\%) & $\begin{array}{c}3,083,024 \\
(48.74 \%)\end{array}$ & $\begin{array}{c}3,242,366 \\
(51.26 \%)\end{array}$ & $\begin{array}{c}6,325,390 \\
(100 \%)\end{array}$ & $\begin{array}{c}11,096 \\
(50.07 \%)\end{array}$ & $\begin{array}{c}11,063 \\
(49.93 \%)\end{array}$ & $\begin{array}{l}22,159 \\
(100 \%)\end{array}$ \\
\hline
\end{tabular}

Source: ESCA survey waves 2010-2015 \& Catalan Institute of Statistics (IDESCAT).

Table 3. Descriptive statistics of the dependent and independent variables.

\begin{tabular}{lccc}
\hline & Male & Female & Total \\
\hline Antidepressants medicines & $3.75 \%$ & $9.01 \%$ & $6.36 \%$ \\
Anxiolytics medicines & $4.99 \%$ & $10.51 \%$ & $7.75 \%$ \\
Depression/Anxiety & $9.38 \%$ & $19.02 \%$ & $14.18 \%$ \\
Risk of having poor mental health (GHQ-12) & $5.72 \%$ & $9.52 \%$ & $7.61 \%$ \\
Self-assessed health (excellent, very good & $84.35 \%$ & $79.58 \%$ & $81.52 \%$ \\
and good) & $58.42 \%$ & $66.28 \%$ & $62.33 \%$ \\
Chronic illness & $16.09 \%$ & $20.19 \%$ & $18.13 \%$ \\
Physical activity & $24.94 \%$ & $16.69 \%$ & $20.83 \%$ \\
Smoking & $94.68 \%$ & $92.31 \%$ & $93.50 \%$ \\
Hours' sleep & 40.34 & 41.57 & 40.95 \\
Age & $17.27 \%$ & $17.17 \%$ & $17.54 \%$ \\
Age 20-35 & $23.14 \%$ & $22.32 \%$ & $21.36 \%$ \\
Age 35-50 & $17.75 \%$ & $17.92 \%$ & $18.37 \%$ \\
Age 50-65 & $10.45 \%$ & $10.45 \%$ & $11.14 \%$ \\
Age 65-80 & $6.99 \%$ & $6.77 \%$ & $7.62 \%$ \\
Age $\geq 80$ & $52.4 \%$ & $44 \%$ & $48.2 \%$ \\
Employed individuals & $58.2 \%$ & $58.4 \%$ & $58.3 \%$ \\
Regions with intensive UR change & $26.4 \%$ & $26.5 \%$ & $26.4 \%$ \\
Private Health Insurance & $33.2 \%$ & $30.6 \%$ & $31.9 \%$ \\
Married & $14.28 \%$ & $14.27 \%$ & $14.28 \%$ \\
Unemployment rate & 13,732 & 13,627 & 27,359 \\
Observations & . & & \\
\hline Sour & &
\end{tabular}

Source: ESCA survey waves 2010-2015, UR source: Catalan Institute of Statistics (IDESCAT). 
Table 4. Marginal effects: logit model for the consumption of psychotropic medicines and mental health outcomes using all the sample.

\begin{tabular}{|c|c|c|c|c|c|}
\hline & \multicolumn{2}{|c|}{$\begin{array}{l}\text { Consumption of psychotropic } \\
\text { medicines }\end{array}$} & \multicolumn{3}{|c|}{ Mental health } \\
\hline & $\begin{array}{l}\text { Antidepressant } \\
\text { medicines }\end{array}$ & $\begin{array}{l}\text { Anxiolytics } \\
\text { medicines }\end{array}$ & $\begin{array}{l}\text { Prob. of suffering } \\
\text { Depression/Anxiety }\end{array}$ & $\begin{array}{c}\text { Risk of poor } \\
\text { Mental Health } \\
\text { (GHQ-12) }\end{array}$ & $\begin{array}{l}\text { Prob. Hours' } \\
\text { Sleep }>6 h\end{array}$ \\
\hline UR & $\begin{array}{l}-0.002 \\
(0.004)\end{array}$ & $\begin{array}{l}-0.001 \\
(0.004)\end{array}$ & $\begin{array}{l}-0.009 \\
(0.006)\end{array}$ & $\begin{array}{l}-0.008 \\
(0.009)\end{array}$ & $\begin{array}{l}-0.008 \\
(0.005)\end{array}$ \\
\hline FE Region & $\mathrm{x}$ & $\mathrm{x}$ & $\mathrm{x}$ & $\mathrm{x}$ & $\mathrm{x}$ \\
\hline FE Year & $\mathrm{x}$ & $\mathrm{x}$ & $\mathrm{x}$ & $\mathrm{x}$ & $\mathrm{x}$ \\
\hline $\begin{array}{l}\text { Individual } \\
\text { Controls }\end{array}$ & $\mathrm{X}$ & $\mathrm{x}$ & $\mathrm{x}$ & $\mathrm{x}$ & $\mathrm{x}$ \\
\hline Obs & 27,316 & 27,316 & 27,315 & 27,316 & 17,500 \\
\hline \multicolumn{6}{|c|}{$\begin{array}{l}\text { Robust standard errors are in parentheses. Significance levels: } * * * p<0.01 ; * * \mathrm{p}<0.05 ; * \mathrm{p}<0.1 \text {. } \\
\text { Note: Results are from a logit model and marginal effects are reported. Individual controls include age group dummies and } \\
\text { gender dummy. See Table } 1 \mathrm{~A} \text { in the appendix for more detailed on the variables included as individual controls. Standard } \\
\text { errors are clustered at the regional unit level. Source: ESCA survey waves } 2010-2015 \text {, UR source: Catalan Institute of } \\
\text { Statistics (IDESCAT). }\end{array}$} \\
\hline
\end{tabular}

Table 5. Marginal effects: logit model for the physical and self-assessed health outcomes and individual health behaviour measures using all the sample.

\begin{tabular}{|c|c|c|c|c|}
\hline & \multicolumn{2}{|c|}{ Physical and self-assessed health } & \multicolumn{2}{|l|}{ Health behaviours } \\
\hline & Chronic illness & $\begin{array}{c}\text { Prob. of reporting } \\
\operatorname{good} \mathrm{SAH}\end{array}$ & $\begin{array}{l}\text { Prob. to practice } \\
\text { Physical Activity }\end{array}$ & Prob. of Smoking \\
\hline UR & $\begin{array}{c}0.003 \\
(0.007)\end{array}$ & $\begin{array}{l}-0.001 \\
(0.006)\end{array}$ & $\begin{array}{l}-0.001 \\
(0.008)\end{array}$ & $\begin{array}{c}0.001 \\
(0.006)\end{array}$ \\
\hline FE Region & $\mathrm{x}$ & $\mathrm{x}$ & $\mathrm{x}$ & $\mathrm{x}$ \\
\hline FE Year & $\mathrm{x}$ & $\mathrm{x}$ & $\mathrm{x}$ & $\mathrm{x}$ \\
\hline $\begin{array}{l}\text { Individual } \\
\text { Controls }\end{array}$ & $\mathrm{x}$ & $\mathrm{X}$ & $\mathrm{x}$ & $\mathrm{x}$ \\
\hline Obs & 27,315 & 27,315 & 27,295 & 27,316 \\
\hline $\begin{array}{l}\text { Robust stand } \\
\text { Note: Result } \\
\text { gender dumn } \\
\text { errors are cl } \\
\text { Statistics (ID }\end{array}$ & $\begin{array}{l}\text { errors are in parenthes } \\
\text { e from a logit model an } \\
\text { See Table } 1 \mathrm{~A} \text { in the ar } \\
\text { ared at the regional un } \\
\text { CAT). }\end{array}$ & $\begin{array}{l}\text { hificance levels: } * * \text { p } \\
\text { inal effects are reporte } \\
\text { for more detailed on } \\
\text { Source: ESCA surve }\end{array}$ & $\begin{array}{l}.01 ; * * \mathrm{p}<0.05 ; * \mathrm{p}<0.1 \\
\text { Individual controls incl } \\
\text { e variables included as } \\
\text { waves } 2010-2015, \mathrm{UR}\end{array}$ & $\begin{array}{l}\text { ge group dummies and } \\
\text { dual controls. Standard } \\
\text { ce: Catalan Institute of }\end{array}$ \\
\hline
\end{tabular}


Table 6. Marginal effects: logit model for the consumption of antidepressants and anxiolytic medicines by different subsamples: gender, age groups, and regions with stronger/softer increases in UR.

\begin{tabular}{|c|c|c|c|c|c|c|c|c|c|}
\hline & Female & Male & $\begin{array}{l}\text { Aged 20- } \\
\quad 35\end{array}$ & $\begin{array}{c}\text { Aged 35- } \\
\mathbf{5 0}\end{array}$ & $\begin{array}{l}\text { Aged 50- } \\
65\end{array}$ & $\begin{array}{c}\text { Aged 65- } \\
80\end{array}$ & Aged 80+ & $\begin{array}{c}\text { Regions } \\
\text { stronger } \\
\text { increase in } \\
\text { UR }\end{array}$ & $\begin{array}{c}\text { Regions } \\
\text { softer } \\
\text { increase in } \\
\text { UR }\end{array}$ \\
\hline \multicolumn{10}{|c|}{ Probability of Consumption; Antidepressant medicines } \\
\hline UR & $\begin{array}{l}-0.001 \\
(0.007)\end{array}$ & $\begin{array}{l}-0.004 \\
(0.003)\end{array}$ & $\begin{array}{l}-0.010 \\
(0.007)\end{array}$ & $\begin{array}{c}0.003 \\
(0.007)\end{array}$ & $\begin{array}{l}-0.006 \\
(0.011)\end{array}$ & $\begin{array}{l}-0.015 \\
(0.015)\end{array}$ & $\begin{array}{c}0.018 \\
(0.013)\end{array}$ & $\begin{array}{l}-0.004 \\
(0.017)\end{array}$ & $\begin{array}{l}-0.004 \\
(0.005)\end{array}$ \\
\hline \multicolumn{10}{|c|}{ Probability of Consumption; Anxiolytics medicines } \\
\hline UR & $\begin{array}{l}-0.002 \\
(0.006)\end{array}$ & $\begin{array}{l}-0.001 \\
(0.003)\end{array}$ & $\begin{array}{c}-0.014 * * * \\
(0.004)\end{array}$ & $\begin{array}{c}0.007 \\
(0.006)\end{array}$ & $\begin{array}{l}-0.011 \\
(0.015)\end{array}$ & $\begin{array}{c}0.003 \\
(0.012)\end{array}$ & $\begin{array}{c}0.007 \\
(0.015)\end{array}$ & $\begin{array}{l}-0.016 \\
(0.012)\end{array}$ & $\begin{array}{c}0.009 * * \\
(0.004)\end{array}$ \\
\hline Obs & 13,610 & 13,706 & 4,537 & 5,836 & 5,017 & 3,047 & 2,079 & 15,912 & 11,404 \\
\hline
\end{tabular}

Robust standard errors are in parentheses. Significance levels: $* * * p<0.01 ; * * p<0.05 ; * p<0.1$.

Note: Results are from a logit model and marginal effects are reported. Fixed effects for regional unit and time controlled for. Individual controls include age group dummies and gender. See Table 1A in the appendix for more detailed on the variables included as individual controls. Standard errors are clustered at the regional unit level. Source: ESCA survey waves 2010-2015, UR source: Catalan Institute of Statistics (IDESCAT). 
Table 7. Marginal effects: logit model for mental, physical and self-assessed health, as well as individual health behaviours by different subsamples: gender, age groups, regions with stronger/softer increase in UR.

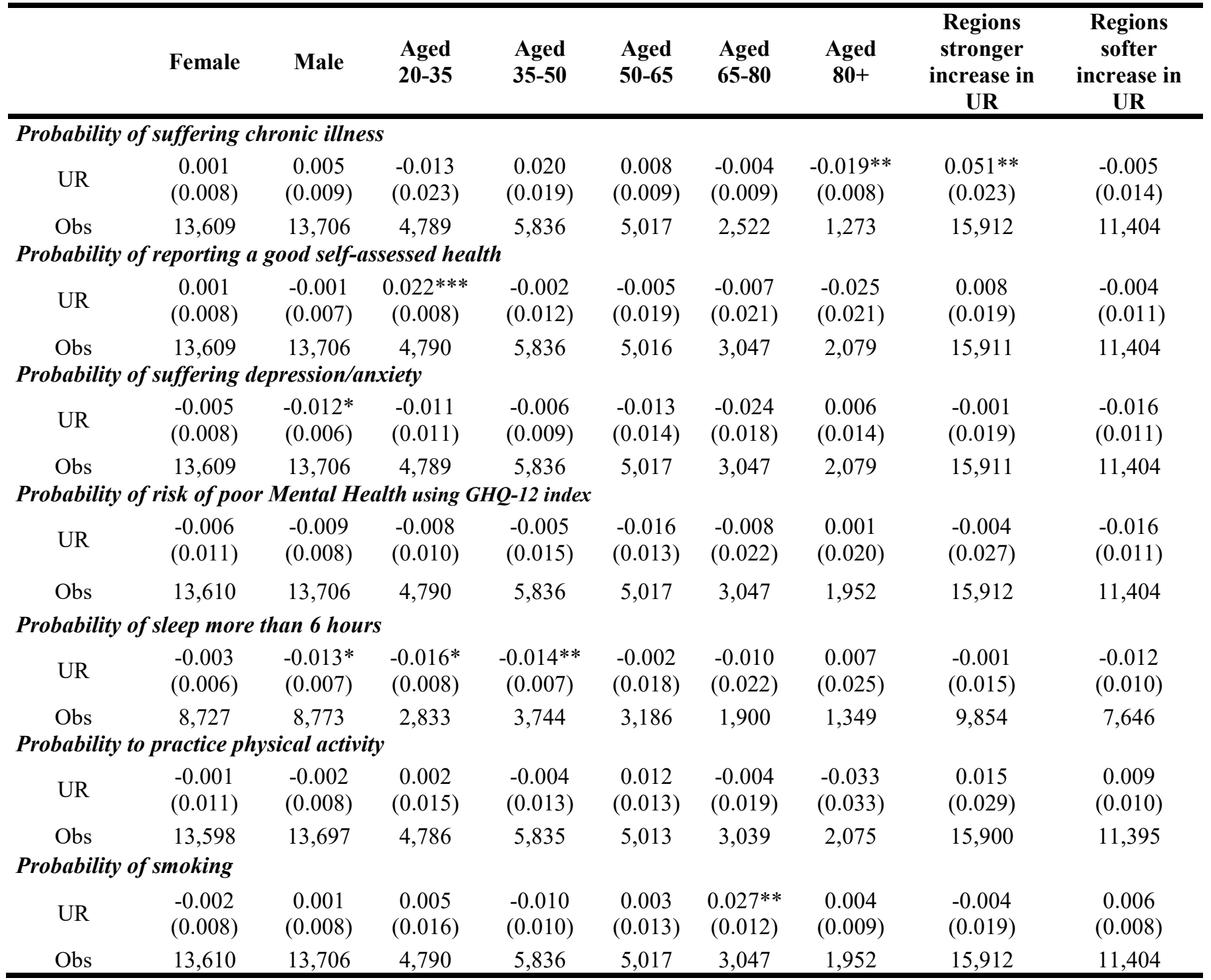

Robust standard errors are in parentheses. Significance levels: ${ }^{* * *} \mathrm{p}<0.01 ; * * \mathrm{p}<0.05 ;{ }^{*} \mathrm{p}<0.1$.

Note: Results are from a logit model and marginal effects are reported. Fixed effects for regional unit and time controlled for. Individual controls include age group dummies and gender. See Table 1A in the appendix for more detailed on the variables included as individual controls. Standard errors are clustered at the regional unit level. Source: ESCA survey waves 2010-2015, UR source: Catalan Institute of Statistics (IDESCAT). 
Table 8. Marginal effects: logit model for the probability of being employed, having private health insurance and for being married by different subsamples: gender, age groups, and regions with stronger/softer increase in UR. OLS regression for net monthly household income.

\begin{tabular}{|c|c|c|c|c|c|c|c|c|c|c|}
\hline & All sample & Female & Male & $\begin{array}{l}\text { Aged } \\
\mathbf{2 0 - 3 5}\end{array}$ & $\begin{array}{l}\text { Aged } \\
\mathbf{3 5 - 5 0}\end{array}$ & $\begin{array}{l}\text { Aged } \\
50-65\end{array}$ & $\begin{array}{l}\text { Aged } \\
65-80\end{array}$ & $\begin{array}{c}\text { Aged } \\
\mathbf{8 0}+\end{array}$ & $\begin{array}{c}\text { Regions } \\
\text { stronger } \\
\text { increases } \\
\text { in UR }\end{array}$ & $\begin{array}{c}\text { Regions } \\
\text { softer } \\
\text { increases } \\
\text { in UR }\end{array}$ \\
\hline \multicolumn{11}{|c|}{ Net monthly household income (OLS estimates) } \\
\hline UR & $\begin{array}{l}-0.053 \\
(0.085)\end{array}$ & $\begin{array}{l}-0.048 \\
(0.088)\end{array}$ & $\begin{array}{l}-0.052 \\
(0.091)\end{array}$ & $\begin{array}{l}-0.047 \\
(0.138)\end{array}$ & $\begin{array}{c}0.119 \\
(0.127)\end{array}$ & $\begin{array}{l}-0.078 \\
(0.146)\end{array}$ & $\begin{array}{c}0.129 \\
(0.089)\end{array}$ & $\begin{array}{l}-0.173 \\
(0.120)\end{array}$ & $\begin{array}{l}-0.024 \\
(0.201)\end{array}$ & $\begin{array}{l}-0.075 \\
(0.123)\end{array}$ \\
\hline Obs & 13,568 & 6,677 & 6,891 & 2,268 & 2,988 & 2,539 & 1,565 & 1,042 & 7,194 & 6,374 \\
\hline \multicolumn{11}{|c|}{ Probability of being employed } \\
\hline UR & $\begin{array}{l}-0.005 \\
(0.006)\end{array}$ & $\begin{array}{l}-0.008 \\
(0.010)\end{array}$ & $\begin{array}{l}-0.003 \\
(0.005)\end{array}$ & $\begin{array}{c}0.015 \\
(0.012)\end{array}$ & $\begin{array}{l}-0.011 \\
(0.013)\end{array}$ & $\begin{array}{l}-0.024 \\
(0.015)\end{array}$ & $\begin{array}{c}0.007 \\
(0.006)\end{array}$ & $\begin{array}{l}-0.091 \\
(0.098)\end{array}$ & $\begin{array}{l}-0.010 \\
(0.014)\end{array}$ & $\begin{array}{l}-0.005 \\
(0.011)\end{array}$ \\
\hline Obs & 22,068 & 9,877 & 11,072 & 4,787 & 5,830 & 5,006 & 2,169 & 1,042 & 12,879 & 9,189 \\
\hline \multicolumn{11}{|c|}{ Probability of having a private health insurance } \\
\hline UR & $\begin{array}{l}-0.008 \\
(0.008)\end{array}$ & $\begin{array}{l}-0.001 \\
(0.011)\end{array}$ & $\begin{array}{l}-0.016^{*} \\
(0.009)\end{array}$ & $\begin{array}{c}0.014 \\
(0.010)\end{array}$ & $\begin{array}{c}-0.032 * \\
(0.018)\end{array}$ & $\begin{array}{c}0.007 \\
(0.017)\end{array}$ & $\begin{array}{c}0.002 \\
(0.020)\end{array}$ & $\begin{array}{l}-0.019 \\
(0.020)\end{array}$ & $\begin{array}{c}-0.035^{* *} \\
(0.017)\end{array}$ & $\begin{array}{c}-0.017 \\
(0.011)\end{array}$ \\
\hline Obs & 27,316 & 13,610 & 13,706 & 4,790 & 5,836 & 5,017 & 3,047 & 2,079 & 15,912 & 11,404 \\
\hline \multicolumn{11}{|c|}{ Probability of being married } \\
\hline UR & $\begin{array}{l}-0.018 \\
(0.016)\end{array}$ & $\begin{array}{l}-0.020 \\
(0.019)\end{array}$ & $\begin{array}{l}-0.016 \\
(0.014)\end{array}$ & $\begin{array}{l}-0.019 \\
(0.025)\end{array}$ & $\begin{array}{c}-0.069^{* *} \\
(0.032)\end{array}$ & $\begin{array}{c}0.005 \\
(0.031)\end{array}$ & $\begin{array}{c}0.015 \\
(0.033)\end{array}$ & $\begin{array}{l}-0.059 \\
(0.040)\end{array}$ & $\begin{array}{l}-0.057 \\
(0.043)\end{array}$ & $\begin{array}{c}0.004 \\
(0.042)\end{array}$ \\
\hline Obs & 21,757 & 10,831 & 10,926 & 3,868 & 4,609 & 3,934 & 2,395 & 1,627 & 12,626 & 9,131 \\
\hline
\end{tabular}

Robust standard errors are in parentheses. Significance levels: $* * * p<0.01 ; * * p<0.05 ;{ }^{*} \mathrm{p}<0.1$.

Note: Results are from a logit model and marginal effects are reported, except for the regression of Net monthly household income where we used OLS estimates. Fixed effects for regional unit and time controlled for. Individual controls include age group dummies and gender. See Table 1A in the appendix for more detailed on the variables included as individual controls. Standard errors are clustered at the regional unit level. Source: ESCA survey waves 2010-2015, UR source: Catalan Institute of Statistics (IDESCAT). 


\section{Appendix}

Table 1A. Description and categorization of the variables included in the analysis.

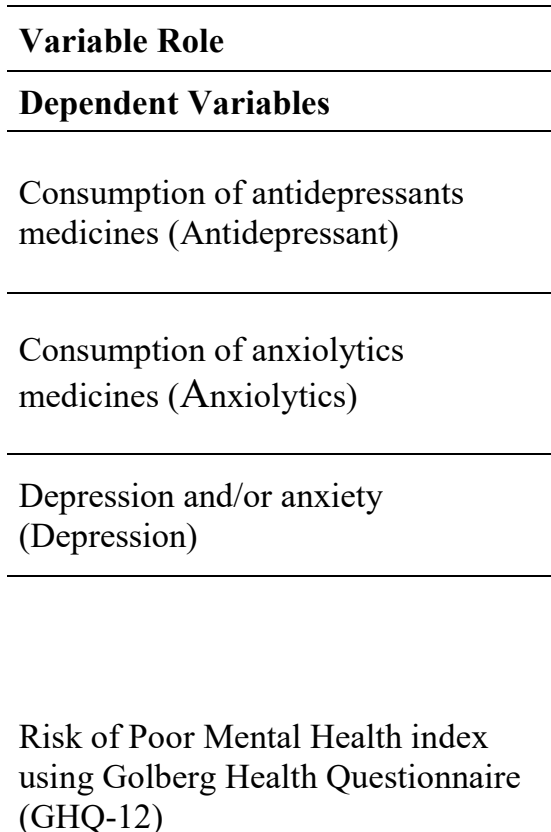

Definition \& comments

Individuals who have consumed or have been prescribed antidepressant medicine in the las two days. This variable takes the value one if the individual claims that he/she has consumed or has been prescribed antidepressant during the las two days and zero otherwise.

Individuals who have consumed or have been prescribed anxiolytics medicine in the las two days. This variable takes the value one if the individual claims that he/she has consumed or has been prescribed an anxiolytic during the las two days and zero otherwise.

A dummy variable in which 1 indicates individuals who reported that they were suffering one or more mental health disorders during the last 12 months and takes 0 otherwise.

The 12-Item General Health Questionnaire (GHQ-12) is the most extensively used screening instrument for common mental disorders, in addition to being a more general measure of psychiatric well-being. The GHQ-12 questionnaire includes 12 questions aimed to detect symptoms of anxiety or depression and it moves on 12-point scales from 0 to 12, i.e. increasing points means worse mental health. Therefore, it is considered that more or equal to 6-point in the scales, the responders have a risk of poor mental health and, otherwise, less than 6-point a normal mental health. These variables are a dummy that takes value zero if the individual have a normal mental health, and one if the individuals have risk of poor mental health.

Dummy variable that takes value one if the individual reported that he/she Self-perceived health status $\quad$ perceived his/her health in the following health status: excellent, very good or good; and 0 if the individual perceived his/her health as regular, bad and No answer/don't know.

Chronic illness A dummy variable equal to one if the individual declares that he/she has had a chronic illness and zero otherwise. A dummy variable equal to one if the individual claims be: more active,

Physical activity moderate active, a bit active or minimum active or zero if the individual is a sedentary.

\begin{tabular}{ll}
\hline Smoking & $\begin{array}{l}\text { A dummy variable dummy that takes value one if the individual smoke, and zero } \\
\text { if the individual: does not smoke. }\end{array}$ \\
\hline Hours of sleep (Hours sleep) & $\begin{array}{l}\text { A dummy variable recoded as one if the individual sleeps more than } 6 \text { hours per } \\
\text { day and zero otherwise. }\end{array}$ \\
\hline Mechanism outcomes & \\
\hline Income & $\begin{array}{l}\text { The net monthly household income is a categorical variable composed by } 10 \\
\text { categories: } 1 \text {. No income (base category); } 2 . \text { Less than } 300 € ; 3 \text {. Between } 301 \text { and } \\
600 € ; 4 . \text { Between } 601 \text { and } 900 € ; 5 . \text { Between } 901 \text { and } 1,200 € ; 6 . \text { Between } 1,201 \\
\text { and } 1,500 € ; 7 . \text { Between } 1,501 \text { and } 1,800 € ; 8 \text {. Between } 1,801 \text { and } 3,000 € ; 9 . \\
\text { Between } 3,001 \text { and } 6,000 € ; 10 . \text { More than } 6,001 € .\end{array}$ \\
\hline Employment status & $\begin{array}{l}\text { A dummy variable dummy that takes value one if the individual is employed, } \\
\text { and } 0 \text { if the individual is not. }\end{array}$ \\
\hline Private health insurance & $\begin{array}{l}\text { A dummy variable dummy that takes value one if the individual has any type of } \\
\text { private health insurance, and zero if the individual only is covered by the Spanish } \\
\text { National Health Insurance. }\end{array}$ \\
\hline
\end{tabular}




\begin{tabular}{|c|c|}
\hline Married & $\begin{array}{l}\text { A dummy variable dummy that takes value one if the individual is married, and } \\
\text { zero otherwise. }\end{array}$ \\
\hline \multicolumn{2}{|l|}{ Independent Variables } \\
\hline Year of the survey (Year) & $\begin{array}{l}\text { We have observations for the following years: year } 2010 \text { (reference category); } \\
\text { year 2011; year2012; year 2013; year 2014; year 2015. }\end{array}$ \\
\hline Age & $\begin{array}{l}\text { We generate dummies for five age groups in our sample: } 20 \text { to } 35 \text { year; } 35 \text { to } 50 \\
\text { years; } 50 \text { to } 65 \text { years; } 65 \text { to } 80 \text { years; } 80 \text { or more. }\end{array}$ \\
\hline Gender & $\begin{array}{l}\text { A dummy variable that takes value one if the individual is a woman and zero if } \\
\text { the individual is a man. }\end{array}$ \\
\hline Regional district (regional unit) & $\begin{array}{l}\text { This variable is composed by } 31 \text { regional districts: 1.Alt Urgell (reference } \\
\text { category), 2.Cerdanya, 3.Pallars Jussà-Pallars Sobirà, 4.Val d'Aran, 5.Segrià, } \\
\text { 6.Alt Camp i Conca de Barberà, 7.Baix Camp, 8.Baix Penedès, 9.Tarragonès, } \\
\text { 10.Ribera de l'Ebre, 11.Baix Ebre, 12.Montsià, 13.Alt Maresme-Selva Marítima, } \\
\text { 14.Baix Empordà, 15.Alt Empordà, 16.Garrotxa, 17.Gironès-Pla de l'Estany, } \\
\text { 18.Ripollès, 19.Anoia, 20.Bages-Solsonès, 21. Berguedà, 22.Osona, 23.Alt } \\
\text { Penedès, 24.Baix Llobregat, 25.Montseny, 26.Barcelonès,,27.Garraf, 28.Vallès } \\
\text { Oriental, 29.Maresme, 30.Vallès Occidental, 31.Alta Ribagorça. }\end{array}$ \\
\hline $\begin{array}{l}\text { Unemployment Rate } \\
\text { (Unemployment) }\end{array}$ & $\begin{array}{l}\text { This variable captures the effects of economics crisis represented by } \\
\text { unemployment rate for Catalan regional units. We use data from IDESCAT. }\end{array}$ \\
\hline
\end{tabular}

